The Internet has changed all of that, sometimes for the better and sometimes not. Yet one cultural legacy of the print-news world still rules: competition. Print readers were the ultimate consumers. Newspapers would compete for their patronage, and to make that happen, newspaper editors would make reporters compete for available space. Reporters would compete with rivals for stories. And anyone with a good story to tell had to compete with a thousand other people to get through to the reporter. The entire news-publishing business was an ever-decreasing circle, with someone on each step in the chain desperate to give the people on the next step exactly what they wanted.

What they all wanted, of course, was a good story - or more accurately, a better story than the other source, reporter, editor or newspaper was offering. Hence, routine speeches by politicians are often described as the most important of their careers, football matches with little at stake are 'must-win' and house prices are perpetually poised between collapse and meteoric rise. Good stories, naturally, are open to a little exaggeration; and a little more at the next step and so on. Newsroom culture demands that the most common phrase exchanged is not "Is this true?" but "Can we say this?"

Here comes the science bit. The reason that any of this matters to Nature is that science stories in the news, or more precisely, health and medical-science stories, are known to influence the behaviour of the people who read them. Together with the collective responsibility that many scientists feel for the way that research is communicated in the media (a responsibility that, say, estate agents seem to lack), this makes media coverage of research an important and muchscrutinized topic.

A study that has been heavily discussed over the past week or so focuses on the bottom step in the news chain described above: the information that universities give to reporters about published research (P. Sumner et al. Br. Med. J. 349, g7015; 2014). The details appear on page 291 of this issue, but can be summarized as follows: exaggeration in press reports of published medical-research papers is also present in press releases sent out by universities to promote those papers.

To conflate, briefly, correlation and causation (which the study counts as exaggeration), it seems that blame for media hype of medical research can be placed as firmly at the door of university press
"There is a demand for straight, lessconventional 'news' about science." offices as on the headline-hungry keyboards of journalists.

Some journalists have nobly resisted the temptation to pass the blame in this way, and insisted that their profession must do more to check the claims made by others before handing them on. Others have called for stricter controls on what universities say, and for scientists who have their work promoted to be held accountable. These are all sensible ideas, and Nature fully supports the idea that researchers should work closely with those who write and circulate press releases on their behalf.

Exaggeration will persist in the news cycle only if it benefits all those involved - from the scientists who can count press coverage as 'impact' to the reporters who bag another high-profile byline and the approving comments of their bosses.

But will it persist? Coming back to the description of newsroom culture, "Can we say this?" is itself giving way to "What else can we say?" as elastic electronic boundaries of news websites replace physical page budgets. The rise (and mass readership) of specialist blogs shows that there is a demand for straight, less-conventional 'news' about science. The implicit benefit of exaggeration - to help stories to squeeze through the next stage in the news process - is weakening.

The study suggests as much - there was no link between the amount of exaggeration in a press release and the media coverage that it received. The truth, in other words, does not have to hurt.

\section{Honest brokers}

\section{Climate negotiations in Lima stumbled on transparency, but there is time to adjust.}

$\mathrm{T}$ he main task for negotiators at the United Nations climate talks in Lima last week was simple: lay out the rules for the emissions pledges that countries will submit over the next six months. Countries had already agreed to put forth plans, each according to its own needs, capabilities and circumstances, and were riding a small wave of optimism after the surprise announcement in the lead-up to the talks that China and the United States had agreed to cut their emissions. The question was how to register and interpret these commitments going into the headline summit in Paris next year.

It is hard to overstate the simplicity of this task, especially relative to the magnitude of the challenge at hand. And yet negotiators went into double overtime fighting old fights, and walked away with something that bears a clear resemblance to nothing.

Negotiators had various options on the table, ranging from a generic registry of commitments to a formal review process in which countries would be expected to provide the relevant data and then defend the adequacy of their pledges. But after days of bickering about what should be required of whom - led by China, which opposed the reviews - they wound up with a text that requires little of anybody.

The final system must allow everybody to evaluate all national commitments and track their progress over time. A treaty that formalizes such an approach would give all countries confidence that their investments are not in vain.

Sure, nations are beginning to take action, but it is the cumulative carbon emissions that matter. The end goal is a world with essentially zero emissions. That is not possible unless all countries play ball. We are in the middle of a trust-building exercise, and the first step is transparency.

One sticking point is that national commitments can (and will) be assessed in various ways. Wealthy countries will measure actual reductions in emissions; rapidly developing countries might opt for reductions from forecast growth. But commitments can also be assessed in terms of cost, either absolute or relative to economic activity, and even on technical capacity for the poorest nations. Both carbon emissions and investments can be assessed relative to population and per-capita income to get at the question of equity, which is at the heart of most disputes in the climate negotiations. All of these measures are legitimate, and academics are already busy with such analyses. But they all depend on one thing: information, which is what was dropped from the Lima agreement.

Some countries are likely to provide the relevant evidence to bolster their cases, but this process must be streamlined and must be required of every country. Governments, scientists and environmentalists will fill in any gaps as best they can over the coming year, but the challenge will only grow. Next year's pledges will probably fall well short of what is needed to prevent the worst impacts of global warming, so commitments will need to be reviewed and updated regularly. Once governments can demonstrate progress, the plan is for them to initiate a virtuous cycle in which better policies and cheaper technologies help to push emissions ever lower.

This will only work, however, if governments can be held accounta- $\rightarrow$ NATURE.COM To comment online, click on Editorials at: go.nature.com/xhunqv ble and independent analysis can identify which policies are working - and which are not. And to do that, the world will need solid data and robust assessments. Simple or not, the treaty to be signed in Paris should recognize as much. 